\title{
AVALIAÇÃO ECOCARDIOGRÁFICA DO EFEITO DA APLICAÇÃO DE MATERIAIS BIODEGRADÁVEIS NO REMODELAMENTO E NA CONTRATILIDADE CARDÍACA EM MODELO ANIMAL DE ISQUEMIA MIOCÁRDICA
}

\author{
Andrelisa M. de Albuquerque ${ }^{\star}$, Daniela D. Carvalho, Karlos A. S. Vilarinho, Pedro P. M. Oliveira, Orlando \\ Petrucci e Lindemberg M. Silveira Filho.
}

\begin{abstract}
Resumo
A insuficiência cardíaca (IC) é uma complicação frequente após infarto agudo do miocárdio (IAM), devido ao remodelamento do músculo cardíaco deflagrado pela isquemia. Estudos têm utilizado biomateriais como ferramentas para atenuar o progresso da miocardiopatia isquêmica. O objetivo desse projeto é verificar se a aplicação de "scaffolds" acelulares biodegradáveis em modelo animal de isquêmia miocárdica (IM) traz benefícios no remodelamento e na contratilidade cardíaca. Foi realizado modelo de IM por toracotomia esquerda e ligadura da artéria interventricular anterior (AIA) em ratos. Após 2 semanas, os animais foram randomizados em três grupos: controle, tratamento com patch de colágeno-fibroína de seda-protocianidina (COL-SF) ou mesmo patch acrescido de material condutor polianilina (COL-SF-PANi). Através de nova toracotomia, os patches foram suturados sobre a área infartada. Os animais foram submetidos à ecocardiografia no pré-tratamento, 2, 4 e 8 semanas após a indução do IAM e, então, sacrificados. Os dados ecocardiográficos obtidos serão avaliados por avaliador externo para se ter uma análise da função contrátil e do remodelamento do ventrículo esquerdo (VE). O estudo encontra-se atualmente em andamento e até 0 momento o modelo tem se mostrado factível e os biomateriais, de fácil aplicação sobre a parede infartada. A obtenção de imagens ecocardiográficas tem sido realizada com sucesso e permitirá as análises planejadas.
\end{abstract}

Palavras-chave: biomateriais, remodelamento, infarto.

\section{Introdução}

Pacientes após IAM podem evoluir com necrose e perda da contratilidade do segmentos afetados. Como compensação, o VE sofre remodelamento, que se associa com o aparecimento progressivo de sintomas de IC e aumento da mortalidade. A aplicação de biomateriais no miocárdio infartado, como "scaffolds" acelulares, capazes de mimetizar a estrutura da matriz extracelular, estimulando respostas celulares e remodelamento mais favorável, tem sido empregada experimentalmente. O objetivo desse estudo é verificar se a aplicação de patch de COL-SF com ou sem PANi associada pode induzir melhora no remodelamento em modelo de IAM em ratos, avaliado por ecocardiografia.

\section{Resultados e Discussão}

Ratos machos Wistar com cerca de $200 \mathrm{~g}$ foram anestesiados com inalação de isoflurano, entubados, colocados em ventilação mecânica e submetidos à toracotomia esquerda no $4^{\circ}$ espaço intercostal, exposição do coração e ligadura da AIA em terço médio com fio de polipropileno 6,0. Após a ligadura, o tórax era fechado. Os animais foram submetidos a ecocardiograma de controle 2 semanas após a indução de IAM continuando no protocolo somente aqueles com área de infartada $>25 \%$ da massa ventricular esquerda. Esses animais foram, então, randomizados em 3 grupos: 1. controle, 2. submetidos a nova toracotomia com implante de patch COL-SF e 3. patch COL-SF-PANi. Os patches foram desenvolvidos por método de compressão plástica por equipe colaboradora. Os animais foram seguidos e submetidos à ecocardiografia com transdutor linear de $10 \mathrm{MHz}$ nas $2^{\underline{a}}$, 4 $4^{\underline{a}}$ e $8^{\underline{a}}$ semanas após 0 tratamento. Também na $8^{\underline{a}}$ semana, foram sacrificados. Até o momento da elaboração deste material, 14 animais estavam no protocolo, sendo submetidos a ecocardiogramas seriados.
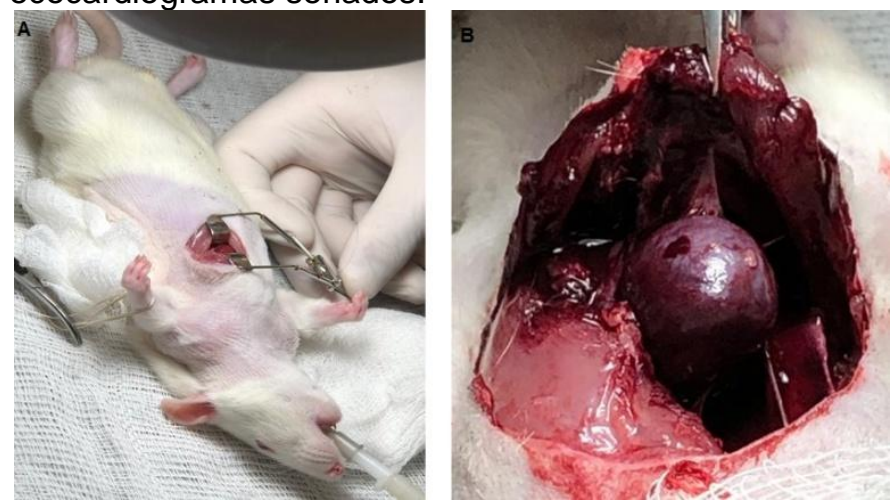

Imagens: A. Toracotomia inicial; B. Coração de animal controle após oito semanas do infarto.

\section{Conclusões}

O implante cirúrgico de ambos os patches tem se mostrado factível e o modelo reprodutível, permitindo que se obtenha amostra de tamanho adequado para as futuras análises. Esperamos ao final dos experimentos, obter dados que mostrem eventual melhora dos parâmetros ecocardiográficos, histológicos e moleculares dos animais tratados com os patches de COL-SF com ou sem PANi.

\section{Agradecimentos}

Agradecemos às equipes do Núcleo de Medicina e Cirurgia Experimental da FCM-UNICAMP e do Laboratório de Biomateriais e Nanotecnologia (LabNus) da Universidade de Sorocaba (Uniso) pela colaboração sem a qual esse trabalho não seria possível.

\footnotetext{
Alves T.F.R.; Souza, J.F.; Severino, P.; Andréo Filho, N.; Lima, R.; Aranha N., Silveira Filho, L.M.; Rai, M. et al. J. Material Sci. Eng. 2018, 7: 5.

${ }^{2}$ D'Amore, A.; Yoshizumi, T.; Luketick S.K.; Wolf M.T.; Gu, X.; Cammarata, M.; Hoff, R.; Badylak S.F. e Wagner, W. R. Biomaterials 2016, 107, 1-14.
} 